\title{
A survey of hygienists qualifying from the Liverpool School of Dental Hygiene $1977-1998$
}

\section{G. Hillam, ${ }^{1}$}

Objectives To analyse the working patterns of all those who qualified from the Liverpool School of Dental Hygiene over a 20 -year period. To assess the proportion who give up practice, the degree of part-time work, career breaks, job satisfaction, availability of continuing professional education etc.

Method A questionnaire sent to all 226 hygienists who qualified from the School between 1997 and 1998, whether still enrolled as dental hygienists or not.

Results Responses were received from $83 \%$ of whom $89 \%$ were still working as hygienists, the majority in general practice. $46 \%$ had taken an employment break, mostly for maternity reasons but a significant number for other reasons. Around $80 \%$ expressed good job satisfaction. Although there is a high level of part-time work, especially after career breaks, few had experienced difficulty in finding employment. One third of respondents considered that the availability of continuing professional education was 'poor' or 'very poor'.

Conclusions The great majority of hygienists enjoy good job satisfaction and work in more than one general dental practice. Comparisons suggest that they continue to work in their chosen career at least as much as female dentists do in theirs. The reasons for this are thought to be that hygienists tend to be recruited from the ranks of highly motivated, mature dental nurses and that the profession lends itself to part-time work which can be combined with family commitments. There are perceived deficiencies in the availability of continuing professional education, which may be remedied by the development of distance learning packages and Section 63 type courses designed specifically for them.

Effective delivery of healthcare involves numerous different factors, not least of which are the selection and training of the most appropriate personnel for the job and the provision of an attractive working environment once qualified. The dental profession is fortunate in that there are ample numbers of young people who wish to train as dentists and hygienists. Nevertheless, the training schools have a responsibility to monitor their methods of recruitment to ensure that their students not only are able to complete their course of study but also that, once qualified, they will have the aptitude and motivation to pursue their chosen profession for a substantial period afterwards and assist its development.

Although we have seen an increasing trend for the proportion of females applying for places as dental students in UK dental schools (Matthews and Scully) ${ }^{1}$ the reverse has not been the case for dental

${ }^{1}$ Consultant in Restorative Dentistry, Director of School of Dental Hygiene, Liverpool University Dental Hospital, Pembroke Place, Liverpool L3 5PS

REFEREED PAPER

Received 22.07.99; accepted 05.11.99

(C) British Dental Journal 2000; 188: 150-153 hygienists. UK schools of dental hygiene continue to receive the great majority of their applications from dental nurses. This is despite the current provision for direct entry for those with GCE 'A' level passes. The dental hygiene profession has traditionally been thought of as an ideal career progression for dental nurses who can combine part-time work with family responsibilities. Also, dental nurses comprise a pool of highly motivated personnel who are very familiar with the nature of the job and its demands. The extent to which family or other commitments affect the professional life of hygienists in terms of part-time employment and return to work is unclear.

In 1988 a survey was conducted of students qualifying from the Liverpool School of Dental Hygiene which aimed to analyse their career patterns over a 10 -year period. ${ }^{2}$ The present paper has similar objectives and includes the same subjects as well those who have qualified since 1988 . The 1988 survey indicated that $22 \%$ of the subjects were not working as dental hygienists and the majority of the remainder worked part time, citing family commitments as the main reason. One of the aims of this study was to assess whether there has been a return to work as dental hygienists after possible reduction in family commitments, as well as to assess job opportunities, access to continuing professional education and job satisfaction.

\section{Materials and method}

The Liverpool School of Dental Hygiene attempts to maintain a comprehensive database of the current addresses of all its exstudents, whether they are working as hygienists or not, in order to maintain social contact, to distribute information on refresher courses and to send an annual newsletter. The newsletter distributed to all 226 alumni (all female) in December 1998

\section{Table 1. Summary of contents of questionnaire}

Q1. Name

Q2. Year of qualification

Q3. Whether still in practice as hygienist

Q4. Other paid employment?

Q5. Using skills or knowledge gained as a hygienist in other paid employment?

Q6. Area of current practice? (Private or NHS practice, hospital, community)

Q7. Number of hours worked per week as hygienist

Q8. Number of practices worked in

Q9. Any career breaks of 3 months or more and reasons for them?

Q10. Job satisfaction on five-point scale

Q1 1. Factors influencing job satisfaction. Respondents were invited to tick any five out the ten factors which particularly apply to them. (See Table 2).

Q12. Ease of finding hygienist employment over the past 5 years, on five-point scale

Q13. Average number of hours worked per week for each year since qualification

Q14. Availability of Continuing Professional Education 
Table 2 Detail from question 11 of the questionnaire. Factors perceived as enhancing or depressing the job satisfaction of dental hygienists (after Bickley) ${ }^{4}$

\begin{tabular}{|c|c|}
\hline $\begin{array}{l}\text { Playing a part in improving } \\
\text { dental health }\end{array}$ & $\begin{array}{l}\text { Lack of patient interest in } \\
\text { oral health }\end{array}$ \\
\hline $\begin{array}{l}\text { Maintaining high clinical } \\
\text { standards }\end{array}$ & $\begin{array}{l}\text { Insufficient time allowed } \\
\text { for appointments }\end{array}$ \\
\hline $\begin{array}{l}\text { Patient communication } \\
\text { and motivation }\end{array}$ & $\begin{array}{l}\text { The repetitiveness of } \\
\text { the job }\end{array}$ \\
\hline $\begin{array}{l}\text { Working with patients to } \\
\text { achieve good oral health }\end{array}$ & $\begin{array}{l}\text { Being perceived as } \\
\text { a 'cleaning machine' }\end{array}$ \\
\hline Patients' appreciation & Low status \\
\hline
\end{tabular}

included a questionnaire. The contents of the questionnaire are summarised in Tables 1 and 2. As an incentive for the return of completed questionnaires all those returning their forms by the end of January 1999 were entered in a draw for a cash prize. A reminder was sent to non-respondents in February 1999 and, where necessary, a second reminder was sent later that month, after ascertaining their most up-to-date addresses from the 1999 Roll of Dental Hygienists as published by the General Dental Council of the UK on the internet.

\section{Results}

Replies were received from 188 of the 226 alumni, a response rate of $83 \%$. Of the respondents, $167(89 \%)$ were working as hygienists and a further $10(5 \%)$ were working in some other paid employment. Four of these ( $2 \%$ of the total) were using some of the knowledge or skills gained from their training as hygienists, as, for example, health promotion manager, dental representative, school matron. Only $11(6 \%)$ were not working.

The great majority of practising hygienists were working in NHS practice, private practice, or a combination of the two. Only 9\% were working in the hospital or community services (Fig. 1). Thirty-four respondents (18\%) worked exclusively in NHS practice, a similar number $(17.5 \%)$ exclusively in private practice and $94(50 \%)$ in a combination of the two.

Subjects were asked to indicate the average number of hours they work per week as hygienists in seven categories (not working, 1-8 hours, 9-16 hours, 17-24 hours, 25-32 hours, 33-40 hours and more than 40 hours). For convenience, the results have been converted to 'average days' of 8 hours, although it is realised that the hours may have been worked as fewer longer days or more shorter

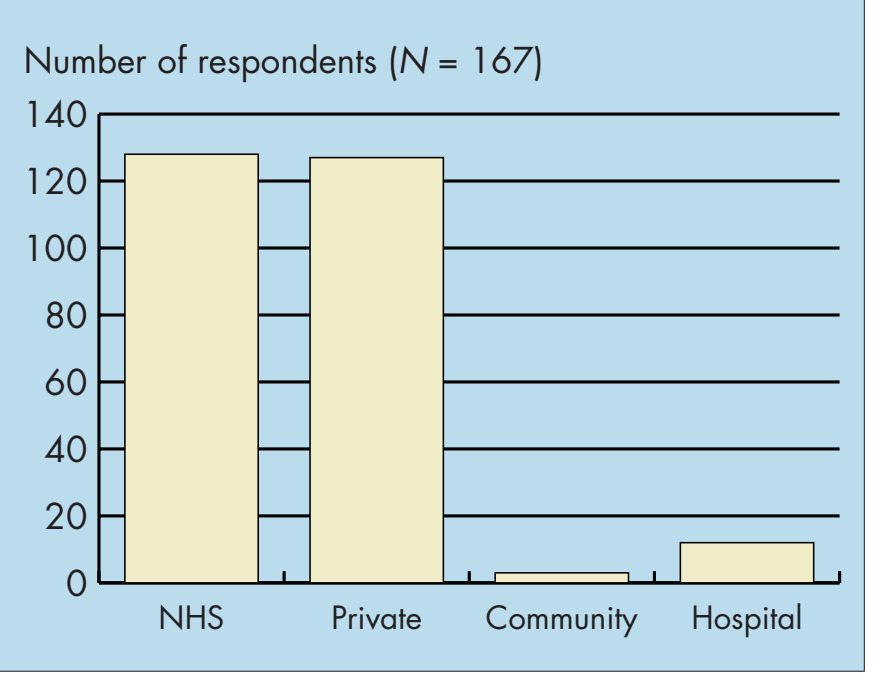

Fig. 1 Types of practice in which hygienists are employed

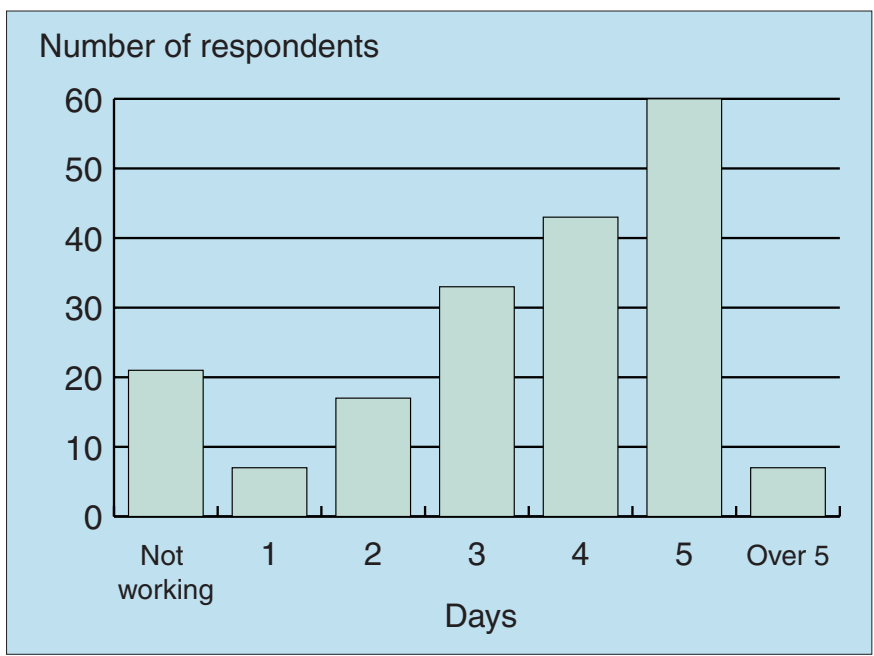

Fig. 2 Average number of days worked per week

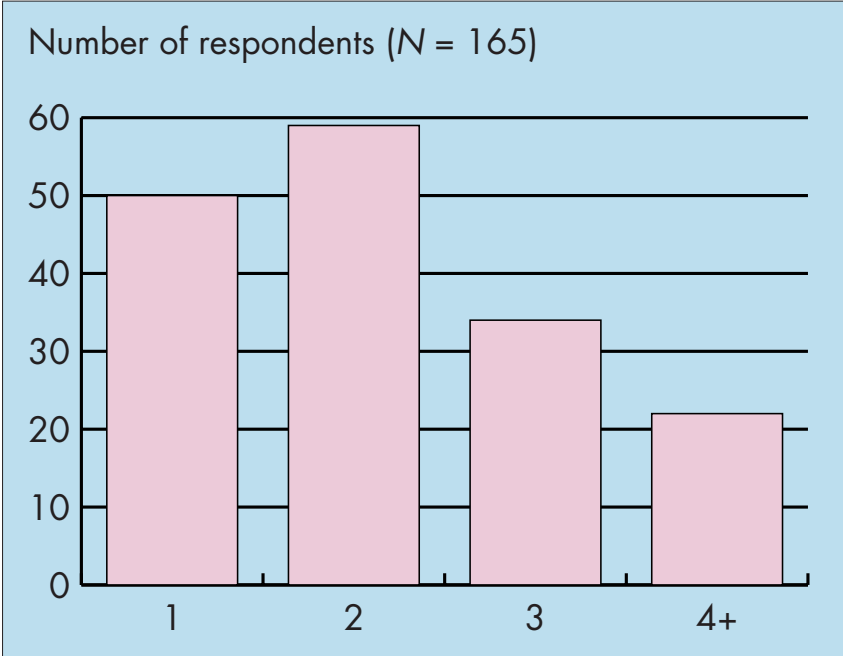

Fig. 3 Number of practices worked in

days. Figure 2 shows that 67 respondents (36\%) work the equivalent of five or more days per week (35+ hours).

Figure 3 shows that 50 (30\%) of the respondents working in general dental practice work in only one practice, $36 \%$ in two, $21 \%$ in three and $13 \%$ in four or more. The average number of practices worked in by each hygienist was 1.73 .

When subjects were asked if they had taken an employment break of 3 months or more, 86 respondents (46\%) indicated that they had. Of these, $74 \%$ indicated that the break was for maternity reasons. In only one instance was an inability to find a job given as the reason for the career break. Reasons given by the remainder included a 'desire to travel' (3), 'fancied a change, 'didn't want to work while children under 5', 'looking after children' (2), job or career change (5), 'abroad and unable to work', 'time to be with husband and animals', 'training for another career' (eg podiatry, dental therapy), 'work in family business', 'illness (7), 'monotony/stress', 'teach in summer camp/USA', 'University course (3), 'needed a change'.

When asked about job satisfaction on a five point scale, $83 \%$ stated that they had good or very good job satisfaction (79\% of those still working as hygienists) whereas only $9.6 \%$ stated poor or very poor (the same percentage as those still working as hygienists). Twenty-nine respondents did not answer this particular question (Fig. 4).

The questionnaire listed five factors which are commonly perceived to enhance job satisfaction and a further five which may 


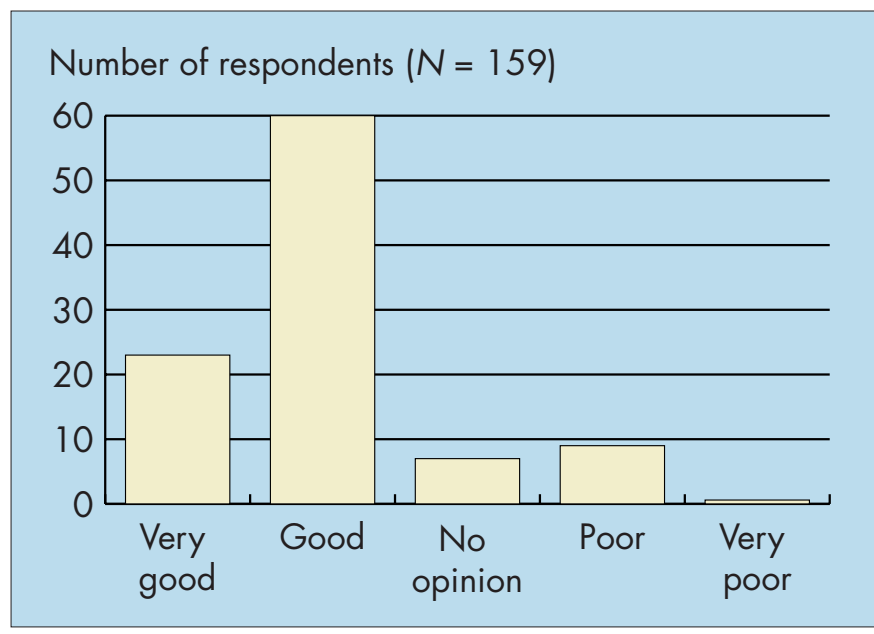

Fig. 4 Job satisfaction

Per cent of respondents $(N=170)$

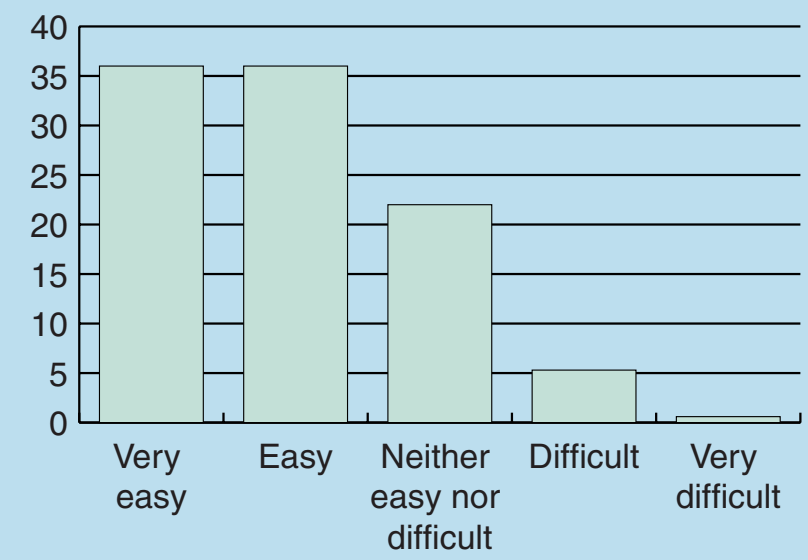

Fig. 5 Ease of finding work

serve to depress job satisfaction. (Table 2). The statements were taken from the UK National Survey of Dental Hygienists. ${ }^{4}$ Respondents were invited to indicate any five of the ten statements which they thought particularly applied to them. On average, they marked 3.4 items from the left-hand list and 1.36 items from the right-hand list, reinforcing the view of good job satisfaction amongst the majority of these hygienists. Table 3 shows the number of responses in each category in ranking order.

The majority of respondents found it easy or very easy to find employment (72\%). Only 10\% reported any difficulty (Fig. 5).

In connection with the availability of continuing professional education, $46.5 \%$ considered it to be good or very good, whereas $33.5 \%$ considered it to be poor or very poor (Fig. 6).

This survey attempted to make a retrospective analysis of the varying amounts of time worked as a hygienist over the individual's practising career. The results show that in the first 4 years after qualification the average hygienist worked for the equivalent of 33 or more hours per week ( 4 or more days). By the definition of Scully and Matthews, ${ }^{3}$ this is full time. The amount of time worked then reduced to about 3 days per week on average until the 7 th year after qualification, thereafter remaining more or less unchanged (Fig. 7).

\section{Discussion}

A major problem in this kind of study is the avoidance of bias. This may arise because the non-responders may contain a higher pro-

\section{Table 3 Number of responses to each factor related to} job satisfaction

\begin{tabular}{lr}
\hline Working with patients to achieve good oral health & 135 \\
Playing a part in improving dental health & 130 \\
Patient communication and motivation & 129 \\
Patients' appreciation & 126 \\
Maintaining high clinical standards & 115 \\
Insufficient time allowed for appointments & 73 \\
The repetitiveness of the job & 69 \\
Being perceived as a 'cleaning machine' & 50 \\
Lack of patient interest in oral health & 38 \\
Low status & 18
\end{tabular}

portion of those who have left practice. Also, most comparable surveys have only included hygienists or dentists who are enrolled or registered with the GDC, ${ }^{3,4}$ therefore missing those individuals who have given up practice and ceased to be enrolled or registered. It is thought that the inclusive nature of this survey, together with its high response rate $(83 \%)$ enhances the validity of the data produced, even though the numbers surveyed are relatively small and limited to Liverpool alumni. This response rate is comparable to that of Matthews and Scully's survey of registered dentists $(78 \%)^{3}$ and considerably better than the national survey of hygienists in $1994(48 \%){ }^{4}$

The majority of dental hygienists are female, the reason being that, traditionally, recruitment to the profession has been largely from the ranks of dental nurses who have been able to see the work of a hygienist at first hand and see it as career progression and a secure, adequately paid job with the opportunity for part time work, if required. Recently, dental hygiene courses have been recognised as higher education and a dual entry system has been introduced, ie direct entry from school with two 'A' level passes or entry from the ranks of dental nurses having a nationally recognised dental nursing certificate. Nevertheless, the majority of applicants are still dental nurses, an increasing proportion of whom also having 'A' levels. This provides a large pool of highly motivated individuals from which to choose future dental hygienists.

In the 1988 survey of Liverpool dental hygienists, 78\% were recorded as still working as dental hygienists and dental health educators. This has increased to $90 \%$ in the current survey. Also, the average number of practices which each hygienist works in has dropped from 2.24 to 1.73 , suggesting that that they are finding it easier to gain employment without having to split their working week among so many different practices. The degree of job satisfaction remains similar between the two surveys (80.5\% expressing satisfaction in 1988 against $83 \%$ in 1999).

Per cent of respondents $(N=181)$

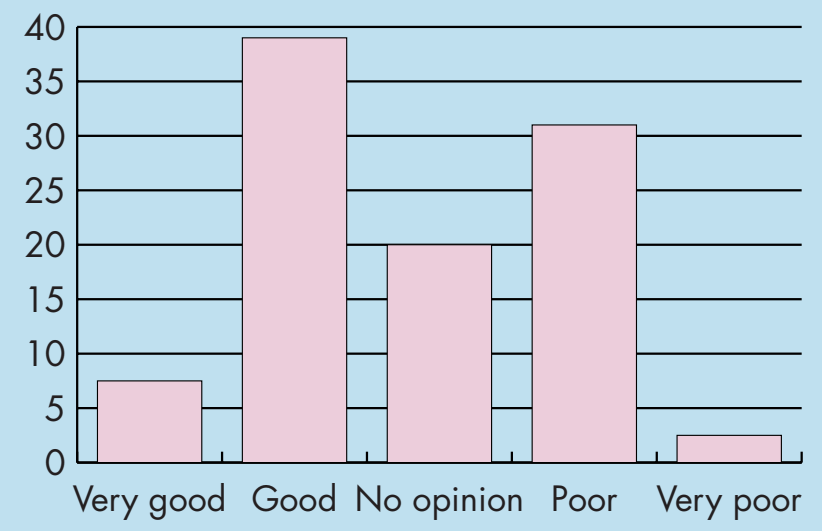

Fig. 6 Availability of continuing professional education 


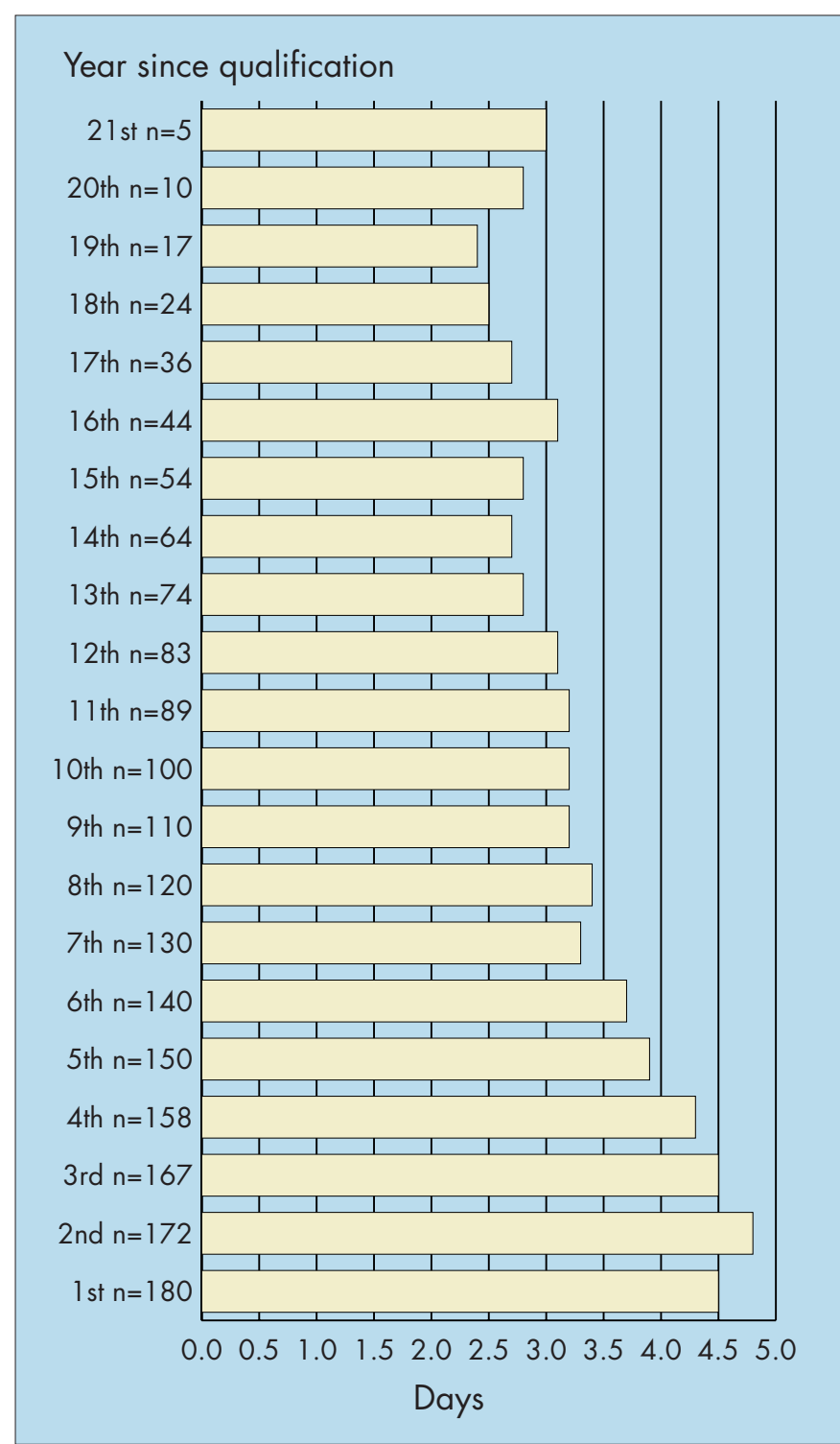

Fig. 7 Average number of days worked each week in each year since qualification

A high proportion of the respondents (46\%) had taken a break of three months or more from work. In the majority of cases this was for maternity reasons. A relatively small number chose to remain at home to look after small children. Another reason frequently given for the break was a desire for a change in career, perhaps to obtain other qualifications, often in a health related field. Some wanted a break simply to spend more time at home or to travel. How much this reflected the stressful nature of the job is difficult to determine. Nor is it possible to deduce from the information received, whether occupational factors were responsible for the illnesses mentioned by seven hygienists (3.7\% of respondents) who gave this as the reason for a break of 3 months or more.

The results of this questionnaire did not support the view which is sometimes expressed but with little objective evidence, that there is a high level of dissatisfaction among hygienists. This survey, as well as those conducted by Bickley in 1994 and Hillam in 1988, indicates that dental hygienists in the UK enjoy good job satisfaction and records a larger number of positive factors in connection with their work than negative ones. Also, they continue in employment at least as much as female dentists. Only $6 \%$ recorded any difficulty in finding work which reinforces the perceived opinion that hygienists are in a 'buyers market' and therefore able to command high salaries, at least in some parts of the United Kingdom. Although there were no financial questions in the questionnaire it is a reasonable assumption that high salaries would improve satisfaction ratings. In the open questions, no respondent indicated lack of reward as being a source of dissatisfaction. On the other hand when the hygienists were invited to indicate any negative aspects associated with their job, 73 (39\%) said insufficient time allowed for appointments' and 69 (37\%) said 'the repetitiveness of the job' which could be said to reflect the financial constraints under which hygienists find themselves obliged to work. This was especially stressed by those working in NHS practice.

While $46.5 \%$ of respondents considered the availability of continuing professional education (CPE) to be 'good' or 'very good', $33.5 \%$ considered it to be 'poor' or 'very poor'. Meetings arranged by the British Dental Hygienists' Association and its regional groups were particularly commended by some hygienists but others mentioned lack of facilities in their own areas. It should be remembered that hygienists do not have a centrally funded scheme similar to Section 63 courses for dentists and the costs of attending courses have to be borne by themselves or by their employing dentists. Most schools of dental hygiene organise refresher courses from time-to-time but without a network of regional tutors, the location of these is not suitable for many of the more remotely placed hygienists. With the current development of the professions complementary to dentistry and the increasing realisation of the need for CPE in all areas of employment, it is clear that more needs to be done to improve these facilities for dental hygienists. One way of improving this situation would be the development of distance learning packages. This would be especially beneficial for those hygienists working in areas remote from a teaching centre.

In comparison with the 1988 survey, there is some indication that hygienists are finding it easier to gain employment immediately on qualification. This is shown by the fact that nearly all work full time from the time of qualification and in fewer practices than 10 years ago. There tends to be an increase in part-time work and career breaks, mostly for maternity and child care reasons. It is difficult to achieve direct comparison between this and other surveys of hygienists and dentists because the latter have been addressed only to people still registered with the GDC, whereas this survey was addressed to all hygienists who had qualified at the Liverpool school. However, there is no indication that hygienists have a greater 'drop out' rate compared with other professions. Indeed, this group compared very favourably with the study of registered male and female dentists by Matthews and Scully which showed that only $46 \%$ of the females were working for 4 or more days per week. ${ }^{3}$ Nevertheless, this survey does show that once hygienists have given up work, or reduced the number of hours worked, they rarely go back to work full time. It would appear that there is sufficient satisfaction in combining part-time work with caring for a family but there is also anecdotal evidence that after a career break, there is a tendency for hygienists to lose some confidence in their abilities and experience difficulty in finding appropriate refresher courses.

Thanks are due to Stafford-Miller Ltd for financial assistance with the costs of this survey and also to the hygienists who responded to the questionnaire. Also, to the staff of the Liverpool School of Dental Hygiene who have assisted in the development and maintenance of a corporate identity over many years, which has assisted in maintaining communication with ex-students.

1 Matthews R W, Scully C. Recent trends in university entry for dentistry in the UK. Br Dent J 1993; 175: 217-219.

2 Hillam D G. Career patterns of dental hygienists qualifying from the Liverpool Dental Hospital School of Dental Hygiene. Br Dent J 1989; 166: 310-311.

3 Matthews R W, Scully C. Working patterns of male and female dentists in the UK. Br Dent J 1994; 176: 463-466.

4 Bickley S R. UK National Survey of Dental Hygienists 1994. Brackley: Partners in Practice. April 1995. 